\title{
ECTOPIC THE OVERRATED DANGER
}

Mangal Santosh Supe ${ }^{1}$, Nilesh Mhaske², Hrishikesh Mandhane, Jayashree Bandar4

${ }_{1}^{1}$ HOD, Department of Obstetrics and Gynaecology, Yashwantrao Chavan Memorial Hospital, Pimpri Chinchwad, Pune. ${ }^{2}$ Speciality Medical Officer, Yashwantrao Chavan Memorial Hospital, Pimpri Chinchwad, Pune.

${ }^{3}$ Senior Resident, Department of Obstetrics and Gynaecology, Yashwantrao Chavan Memorial Hospital, Pimpri Chinchwad, Pune. ${ }^{4}$ Resident, Department of Obstetrics and Gynaecology, Yashwantrao Chavan Memorial Hospital, Pimpri Chinchwad, Pune.

\section{ABSTRACT}

\section{BACKGROUND}

Motherhood an eternal, universal and inherent dream which every woman has!! This dream may not always be pleasant and it can involve tragedies as well. One of this is ectopic pregnancy, a pregnancy which can be life-threatening in a flash if not managed well and on time. The present study involves a study on all the cases of ectopic pregnancy who were admitted to the Yashwantrao Chavan Memorial Hospital during November 2016 to April 2017.

\section{MATERIALS AND METHODS}

A total of 50 patients who were referred and diagnosed as ectopic pregnancy cases were analysed between the period from November 2016 to April 2017. The study design is case series- All these cases were analysed after applying the inclusion and exclusion criteria with respect to the: 1 . History, 2 . Clinical presentation, 3. Investigations, and 4. Treatment.

\section{RESULTS}

The incidence of the ectopic pregnancy in the present study was 1:257 deliveries. The majority of the cases were multigravidas. In most of the cases, there were no identifiable risk factors. However, they did present with pain in the abdomen, amenorrhea and spotting per vagina in more than $80 \%$ of the cases. Almost, $52 \%$ were in a state of shock at admission. Ultrasound, a urine pregnancy test and culdocentesis were the investigative modalities which were used. All the cases were managed by surgical management. On laparotomy, a majority of the cases were found to be ampullary pregnancies followed by isthmic pregnancies. The tube was ruptured in $92 \%$ of the cases and there was a haemoperitoneum. Almost all the patients required intraoperative and/ or postoperative blood transfusions. There was only one case with post-operative morbidity in included cases.

\section{CONCLUSION}

The early diagnosis of an ectopic pregnancy is one of the greatest challenges for Gynaecologists in a day-to-day clinical practice. It requires a high index of suspicion as said in a saying, "You have to be Ectopic Minded to Diagnose an Ectopic Pregnancy." To diagnose and treat ectopic conservatively gives hope for future fertility, but in case of our study centre being the referral centre very few of about $4 \%$ patients could be offered conservative line of management. At conclusion of the study, we have not found any significant increase or decrease in the incidence of ectopic pregnancy compared to in the past.

\section{KEY WORDS}

Ectopic the Overrated Danger.

HOW TO CITE THIS ARTICLE: Supe MS, Mhaske N, Mandhane H, et al. Ectopic the overrated danger. J. Evolution Med. Dent. Sci. 2018;7(27):3103-3105, DOI: 10.14260/Jemds/2018/697

\section{BACKGROUND}

Ectopic pregnancy is defined as any intra- or extra-uterine pregnancy, in which the fertilised ovum implants at an aberrant site, which is non-supportive to its growth and development. ${ }^{1}$ Ectopic pregnancy is assuming greater importance because of its increasing incidence and its impact on women's fertility.2,3 Ectopic pregnancy remains the leading cause of maternal morbidity and death in early pregnancy. 4

With respect to the management of ectopic pregnancy, there have been tremendous technical advances in modern obstetrics and gynaecology. The early diagnosis and

Financial or Other, Competing Interest: None.

Submission 27-04-2017, Peer Review 15-08-2017,

Acceptance 21-08-2017, Published 02-07-2018.

Corresponding Author:

Dr. Mangal Santosh Supe,

Flat No. 1, Sai Prasad Apartment,

Survey No. 70/1, Samtanagar,

New Sanghavi, Pune-411027.

E-mail: drmangalbhokte28@gmail.com

DOI: $10.14260 /$ jemds $/ 2018 / 697$ treatment of this condition over the past two decades has allowed a definitive medical management of unruptured ectopic pregnancies even before there were clinical symptoms in these high-risk women.5,6

The current trend is a conservative way of management of these pregnancies, be it chemotherapeutic agents or conservative surgical approaches, the ultimate goal is tubal conservative procedures rather than radical surgeries. 7,8

\section{Objectives}

1. To know the age group, parity and the risk factors with respect to the ectopic pregnancy.

2. To know the clinical presentation of the ectopic pregnancy.

3. To know the outcome of the ectopic pregnancy.

\section{MATERIALS AND METHODS}

\section{Source of the Data}

This study was undertaken at Yashwantrao Chavan Memorial Hospital, Pune, a total of 50 patients who were referred and diagnosed as ectopic pregnancy cases were analysed between 
November 2016 and April 2017, after obtaining ethical committee clearance from the hospital authorities. The Data Source included the women in the reproductive age group (15 - 40 years) who were admitted here with diagnosis of an ectopic pregnancy.

\section{Study Design}

Case series.

\section{Methods of Collection of the Data}

All the women with ectopic pregnancies (who were already diagnosed and referred and diagnosed after a clinical examination and investigations) were included in the study.

\section{Inclusion Criteria}

All the women who were diagnosed as ectopic pregnancy cases in the reproductive age.

\section{Exclusion Criteria}

No specific exclusion criteria involved.

\section{RESULTS}

- A total of 50 cases of ectopic pregnancies were diagnosed.

- The incidence of ectopic pregnancy in the present study was 1: 257 deliveries.

- A majority of the patients (98\%) belonged to the 21 - 30 years' age group.

- $12 \%$ were primigravida and the rest $88 \%$ were multigravida.

- A majority of the cases presented with pain in the abdomen (86\% of cases); amenorrhea (80\%) and spotting (46\%).

- About $52 \%$ of the cases were brought in a state of shock.

- Cervical motion tenderness was present in $74 \%$ of the cases and the forniceal masses were present in $68 \%$ of the cases.

- $\quad$ The urinary pregnancy test (UPT) was positive in $98 \%$ of the cases and culdocentesis was positive in $78 \%$ of the cases.

- Ultrasound revealed a ruptured ectopic pregnancy in $96 \%$ of the cases; an un-ruptured pregnancy in $4 \%$ of the cases. In $78 \%$ of the cases, a fluid was noted in the Pouch of Douglas.

- A majority of the cases were ampullary pregnancies (80\%). Ovarian ectopic in $8 \%$ of the cases, isthmic pregnancies in $8 \%$ of the cases and cornual pregnancy was seen in $4 \%$ of the cases.

- Total of $92 \%$ showed a ruptured ectopic pregnancy on laparotomy. Tubal abortion was seen in 1 case and an unruptured ectopic pregnancy in 1 case.

- All of $88 \%$ cases showed a haemoperitoneum on laparotomy.

- The most common procedure which was done was salpingectomy in almost $92 \%$ of the cases, followed by salpingo-oophorectomy in about $8 \%$ of the cases.

- Most of these cases (96\%) had blood transfusions intraoperatively and post-operatively.

- The postoperative period was uneventful, except 1 case which developed pulmonary oedema causing breathlessness and requiring ICU management.

\begin{tabular}{|c|c|c|}
\hline Authors & Year & Incidence \\
\hline Vinaya Pendse & 1976 & $1: 266$ \\
\hline D'Mello & 1988 & $1: 214$ \\
\hline ICMR & 1990 & $1: 250$ \\
\hline Present Study & $2016-17$ & $1: 257$ \\
\hline \multicolumn{2}{|r|}{ Table 1. Comparison of Incidence } \\
\hline
\end{tabular}

\begin{tabular}{|c|c|c|}
\hline Findings & $\begin{array}{c}\text { Rose et al } \\
\text { (2002) }\end{array}$ & $\begin{array}{c}\text { Present Study } \\
\text { (2016-17) }\end{array}$ \\
\hline Tenderness & $83.9 \%$ & $74 \%$ \\
\hline Mass in fornix & - & $68 \%$ \\
\hline $\begin{array}{c}\text { Cervical motion } \\
\text { tenderness }\end{array}$ & $49.5 \%$ & $74 \%$ \\
\hline \multicolumn{2}{|c|}{ Table 2. Comparison of Clinical Findings } \\
\hline
\end{tabular}

\begin{tabular}{|c|c|c|c|}
\hline Site & $\begin{array}{c}\text { Chow et al } \\
(\mathbf{1 9 8 7 )}\end{array}$ & $\begin{array}{c}\text { Rose et al } \\
(\mathbf{2 0 0 2 )}\end{array}$ & $\begin{array}{c}\text { Present Study } \\
(\mathbf{2 0 1 6 - 1 7 )}\end{array}$ \\
\hline Ampulla & $79.6 \%$ & $56.9 \%$ & $80 \%$ \\
\hline Isthmus & $12.3 \%$ & $39.78 \%$ & $8 \%$ \\
\hline Cornual & $1.9 \%$ & $1.07 \%$ & $4 \%$ \\
\hline Ovarian & & $8 \%$ \\
\hline \multicolumn{3}{|c|}{ Table 3. Comparison of Site of Ectopic Pregnancy } \\
\hline
\end{tabular}

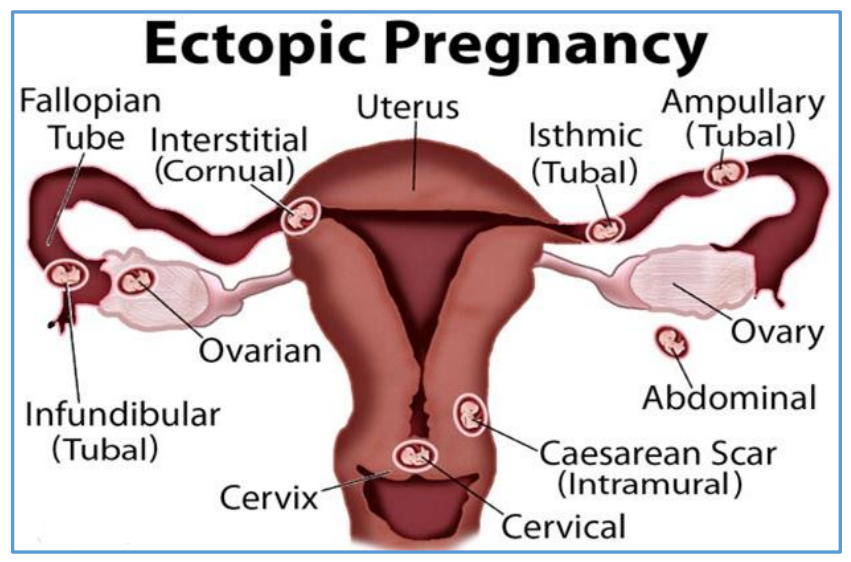

\begin{tabular}{|c|c|c|c|}
\hline & $\begin{array}{c}\text { Wills and } \\
\text { Mohambal }\end{array}$ & $\begin{array}{c}\text { Savitha } \\
\text { Devi }\end{array}$ & $\begin{array}{c}\text { Present } \\
\text { Study }\end{array}$ \\
\hline Ruptured & $66 \%$ & $30.77 \%$ & $92 \%$ \\
\hline $\begin{array}{c}\text { Un- } \\
\text { ruptured }\end{array}$ & $34 \%$ & $69.23 \%$ & $8 \%$ \\
\hline \multicolumn{3}{|l|}{ Table 4. Comparison of Presentation of Ectopic Pregnancy } \\
\hline
\end{tabular}

\section{DISCUSSION}

\section{Incidence}

The incidence of ectopic pregnancy has increased since the last 20 years. The incidence in the present study is 1: 257 deliveries [Table 1].

\section{Clinical Symptoms}

The classical findings of pain in the abdomen, amenorrhea and vaginal bleeding are seen in most of the cases. This is because the clinical picture is dependent on several factors, the most important factor being the time which is taken for a disturbance to occur in the ectopic pregnancy. The more extensive and rapid the disturbance is the clearer is the clinical picture and symptomatology.

Suspicion of the ectopic pregnancy is considered in cases presenting typically with clinical triad in ectopic pregnancy. On the other hand an un-disturbed, un-ruptured ectopic pregnancy is more likely to be missed unless it is diagnosed by ultrasonography. ${ }^{9}$ 


\section{General Physical Examination}

In the present study, most of the cases (52\%) presented with shock as compared to those in other studies. This was because a majority of the cases (92\%) presented with a ruptured ectopic pregnancy. Pallor was a significant finding which was seen in almost $80 \%-84 \%$ of the cases. Thus, general examination is always hinting towards the diagnosis and also the condition of the tube. ${ }^{10}$

\section{Management}

In the present study as the study centre being the referral unit, most of the cases referred were of a ruptured ectopic pregnancy. They were taken up for laparotomy and most frequently performed operation being salpingectomy.

\section{The other Procedures which were done were}

1. Laparoscopic salpingectomy $8 \%$.

2. Cornual excision and repair in $4 \%$ (These were cases of Cornual pregnancies with rupture).

3. Milking for tubal abortion in $4 \%$.

\section{CONCLUSION}

The incidence of ectopic pregnancies is seen high in the study or it may be a falsely high in evaluation as the study centre being referral unit and is evident in findings of this study. All the cases were diagnosed with a high index of clinical suspicion and the ultrasonography (USG) findings adding to the diagnosis. Though the recent trend in the management of ectopic pregnancy is the use of a conservative surgical or medical line of management, but radical surgery or salpingectomy was the treatment modality which was used in the present study as primary modality of treatment. This was mainly in view of ruptured ectopic pregnancies (92\%) as the majority of the cases were referred and so presentation was late to the emergency room of hospital. But fortunately, there was just a single case with morbidity and not a single mortality suggesting.
"Ectopic related morbidity and mortality can be controlled with high degree of suspicion for Ectopic and vigilant and timely management with proper protocols."

\section{REFERENCES}

[1] Telinde's operative gynaecology. $8^{\text {th }}$ edn. Philadelphia: Lippincott-Raven 1997:501-27.

[2] Ectopic pregnancy-United States, 1990-92. JAMA 1995;273:533.

[3] Rajkhowa M, Glass MR, Rutherford AJ, et al. Trends in the incidence of ectopic pregnancy in England and wales from 1966-1996. Br J Obstet Gynaecol 2000;107(3):369-74.

[4] Department of Health: why mothers die: a confidential enquiry into the maternal deaths in the United Kingdom. In: Drife J, Lewis G. (eds): Norwich, UK: HMSO, 2001:282.

[5] Stovall TG, Ling FW, Buster JE. Outpatient chemotherapy of unruptured ectopic pregnancies. Fertil Steril 1989;51(3):435-8.

[6] Stovall TG, Ling FW, Gray LA, et al. Methotrexate treatment of unruptured ectopic pregnancies: a report of 100 cases. Obstet Gynaecol 1991;77(5):749-53.

[7] Sultana CJ, Easley K, Collins RL. Outcome of laparoscopic versus traditional surgeries for ectopic pregnancies. Fertil Steril 1992;57(2):285-9.

[8] Delacruz A, Cumming DC. Factors determining fertility after conservative or radical surgical treatment for ectopic pregnancy. Fertil Steril 1997;68(5):871-4.

[9] Cacciatore B, Stenman UH, Yiostalo P. Diagnosis of ectopic pregnancy by vaginal ultrasonography in combination with a discriminatory serum hCG level of 1000 IU/L (IRP). Br J Obstet Gynaecol 1990;97 (10):904-8.

[10] Stabile J, Grudzinskas JG. Ectopic pregnancy: a review of incidence, etiology and diagnostic aspects. Obstet Gynaecol Surv 1990;45(6):335-47. 